\title{
Non-Receptor Tyrosine-Protein Kinase TYK2
}

National Cancer Institute

\section{Source}

National Cancer Institute. Non-Receptor Tyrosine-Protein Kinase TYK2. NCI Thesaurus.

Code C101548.

Non-receptor tyrosine-protein kinase TYK2 (1187 aa, $134 \mathrm{kDa}$ ) is encoded by the human TYK2 gene. This protein is involved in both tyrosine phosphorylation and signal transduction. 